\title{
Rescatar la retórica: Del progreso regresivo de las masas a la servidumbre tribal en red ${ }^{1}$
}

\section{Restoring rhetoric: From the regressive progress of the masses to tribal servitude on the Internet}
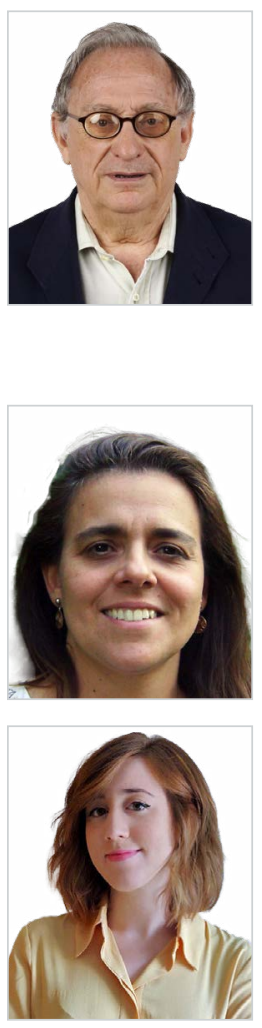

Luis Núñez Ladevéze. Catedrático de la Universidad Complutense (jubilado). Profesor emérito extraordinario de la Universidad San Pablo CEU. Coordinador del Programa de Doctorado en Comunicación Social de CEINDO. Seis sexenios de investigación. Seis proyectos de I+D como IP desde el 2000. Presidente honorario y fundador de la Asociación Internacional de Investigadores. Fundador y presidente del consejo editorial de Doxa Comunicación. Índices i10 24 y h 16. Presidente Consejo Asesor del Instituto de las Artes de la Comunicación TRACOR. Consejero del Consejo de Universidades. Vocal en Ciencias Sociales en ANECA, ACAP, ACADEMIA, ANEP, CENAI, AQU, ACSUG, ACSUCYL, ICMEDIANET. Doctor en Derecho. Licenciado y estudios de doctorado en Filosofía y Letras. Licenciado en Ciencias de la Información. 25 tesis doctorales.

Universidad CEU San Pablo, Madrid, España

ladeveze@telefonica.net

ORCID: 0000-0002-5684-9885

Margarita Núñez Canal. Doctora en Comunicación por la Universidad CEU San Pablo (2013). Profesora investigadora de ESIC Business\&Marketing School España. Investigadora del proyecto CONVERED: CSO2016-74980-C2-1-R "De la cultura de masas a las redes sociales: convergencia de medios en la sociedad digital”. Director Excellence in Teaching \& Learning en ESIC Business\&Marketing School, España.

ESIC Business\&Marketing School, Madrid, España

margarita.nunez@esic.edu

ORCID: 0000-0002-5377-1592

María Navarro Robles. Becaria FPU del Programa de Doctorado en Comunicación Social de CEINDO e investigadora en formación del mencionado Programa. Grado en Publicidad y Relaciones Públicas por la Universidad San Antonio de Murcia. Posee un Máster en Máster en Dirección de Publicidad Integrada por la Universidad Antonio de Nebrija. En la actualidad forma parte del equipo de trabajo del proyecto CONVERED: CSO2016-74980-C2-1-R “De la cultura de masas a las redes sociales: convergencia de medios en la sociedad digital". Ha presentado una Comunicación al el IV Congreso Comunicación y Pensamiento. Sevilla 10-12 abril 2019.

Universidad CEU San Pablo, Madrid, España

maria.navarrorobles@ceu.es

ORCID:0000-0002-7813-539X

1 Artículo financiado por los proyectos C2-1-R, "De la cultura de masas a las redes sociales: convergencia de medios en la sociedad digital", Fondos FEDER y el Programa de actividades PROVULDIG2-CM “Nuevos escenarios de vulnerabilidad digital: alfabetización mediática para una sociedad inclusiva” Ref: H2019/ HUM-5775, financiado la CAM y Fondo Social Europeo

\footnotetext{
Cómo citar este artículo:

Núñez Ladevéze, L.; Núñez Canal, M. y Navarro Robles, M. (2021). Rescatar la retórica: Del progreso regresivo de las masas a la servidumbre tribal en red. Doxa Comunicación, 33, pp. 19-37.
}

https://doi.org/10.31921/doxacom.n33a925 
Recibido: 03/02/2021 - Aceptado: 29/05/2021 - En edición: 03/09/2021 - Publicado: 01/12/2021

\section{Resumen:}

El ilimitado alcance de relaciones cara a cara que se agrupan con distintos grados de cohesión en la red social, cuyos procesos de interacción son tan análogos a los que Cooley llamó los "grupos primarios", ha favorecido todo tipo de prácticas comunicativas. Los más turbios excesos han pasado a ser modos cotidianos de persuasión. Fake news y posverdad, anglicismos novedosos que han saltado al lenguaje corriente. La red se ha convertido en un escenario retórico de interacción a distancia tan compleja como a veces fugaz, en que se desdibujan las diferencias entre información veraz, rumor, bulo y opinión solvente. Nos proponemos revisar La rebelión de las masas y la noción de "aldea global” de McLuhan contrastándolas con Retrotopía, obra póstuma donde Bauman describe el entorno de la red como una "vuelta a las tribus" en el que el usuario asume una "servidumbre voluntaria". La revisión nos sirve también de marco fenomenológico para argumentar sobre la importancia de una recuperación social de las artes retóricas clásicas en la red.

\section{Palabras clave:}

Grupos primarios; retórica; rebelión de las masas; populismo; aldea global; servidumbre voluntaria.
Received: 03/02/2021 - Accepted: 29/05/2021 - Early access: 03/09/2021 - Published: 01/12/2021

\section{Abstract:}

The unlimited range of face-to-face relationships agglomerated with varying degrees of cohesion on social networks, with interactive dynamics that are highly analogous to what Cooley called "primary groups," has fostered an infinite variety of communicative practices. The most muddled excesses have become everyday means of persuasion. Fake news and post-truth are novel anglicisms that have leaped into everyday language. The Internet has become a rhetorical stage for longdistance interaction as complex as it is sometimes fleeting, in which the distinction between truthful information, hearsay, chicanery, and reliable opinion has been blurred. We have set out to review The Revolt of the Masses (La rebelión de las masas), as well as McLuhan's notion of the "global village", by contrasting them with Bauman's posthumous work, Retrotopia, in which he describes the Internet environment as a "return to the tribes" in which the user accepts "voluntary servitude." This review also serves as a phenomenological framework for deliberating the importance of a social revival of the classic art of rhetoric on the Internet.

\section{Keywords:}

Primary groups; rhetoric; revolt of the masses; populism; global village; voluntary servitude.

\section{Introducción a la noción de "progreso regresivo"}

Usamos la expresión "progreso regresivo" para contraponer un concepto teleológico de progreso, propuesto por el "progresismo" ilustrado, a un criterio empírico de progreso que se atiene al enriquecimiento social generado por el acelerado potencial de los procesos industriales de producción. El progresismo entiende por progreso el advenimiento de la armonía social, primero, a través de la educación y, después, mediante un plan político que democratice la sociedad y acabe con las diferencias de clase. El oxímoron "progreso regresivo" denota la coincidencia de los autores examinados en que el progresismo es ilusorio y el progreso tecnológico-científico no contribuye a ligar la autonomía individual a un devenir de fraternidad universal".

Desde la perspectiva pragmática adoptada por la filosofía de la técnica de Ortega y Gasset (en adelante Ortega) compartida por McLuhan (Núñez Canal y Núñez Ladevéze, 2021), no hay enlace de un plan político a un desenlace predeterminado sin forzar la voluntad de los involucrados en el plan. Esta conexión es contradictoria con la armonía pretendida porque no puede asegurar que las consecuencias de la coacción no sean más perniciosas que beneficiosas para su cumplimiento. Para ambos, el progreso

2 Los revisores recomendaron una introducción y que se aclarara la expresión "progreso regresivo" que los autores confiaron a la desenvoltura del texto. Agradecen la sugerencia de precisar objetivos y anticipar el sentido del oxímoron. 
social está ligado a la eficiencia tecnológica en tanto aplicación del conocimiento científico, que es ajeno a la planificación social (Popper, 1961). En su revisión de la sociedad líquida, Bauman acaba concluyendo que, en la globalización tecnológica, no hay suelo firme para sustentar una expectativa democrática basada en un decurso igualitario inmanente a un plan político. El análisis de estos autores coincide -abstrayendo matices- en que el progreso tecnológico avanza en la sociedad global aparejado a un regreso a circunstancias propias de sociedades primitivas. Progresar retrocediendo al pasado sin avanzar hacia una sociedad "progresista", puede expresarse mediante el oxímoron "progreso regresivo".

El progreso del capitalismo industrial "evapora” -en expresión de Marx³ - el pasado. Es el punto de partida del análisis de Bauman de la "sociedad liquida". Según Ortega y McLuhan el pasado permanece de modos diversos. "El hombre-masa cree que la civilización en que ha nacido es tan espontánea y primigenia como la Naturaleza, e ipso facto se convierte en primitivo" (IV, p. 429). Denominamos "progreso regresivo" en Ortega a esta creencia del hombre civilizado que vive su circunstancia tecnológica como si fuera natural con la misma ingenuidad que un "primitivo" entiende que "lo natural" es vivir en su cueva. Al insertarse de este modo en el entorno eléctrico urbano, su actitud ante el progreso tecnológico le viene no menos dada que a un hombre primitivo le viene dada su aldea, dice McLuhan. Su obra describe un progreso que regresa a las circunstancias comunicativas propias de la aldea tribal.

Bauman lamenta que la interdependencia global de la tecnología no pueda compatibilizar una teleología que armonice la autonomía personal con el postulado de solidaridad universal. Los cambios científico-técnicos y los avances socioeconómicos consolidan la "rehabilitación del modelo tribal de comunidad" (2017, p. 18) que el progresismo post ilustrado se proponía superar. Todos los capítulos de Retrotopía se titulan "vuelta” por entender que en la interdependencia global no hay signos para confiar en un avance hacia la fraternidad humana. El progreso tecnológico fortalece el ansia de dominio sin contribuir a una conciencia cosmopolita. Las redes fortalecen la identidad de agrupaciones tribales y de nacionalismos vulnerables al populismo militante.

Ortega detecta en el aude sapere, -atrévete a opinar por ti mismo- el riesgo de que la opinión individual se convierta en juicio crítico sin fundamento para desacreditar a título propio cualquier lazo de solidaridad establecido por la autoridad, sea democrática o tradicional, y advierte que la formación de opinión pública, expuesta al "deletéreo poder de los demagogos [...] para poder alcoholizar a las masas" (De Europa meditatio quaedam, X, p. 114) pueda servir de cauce regresivo a un "primitivismo" masificado.

McLuhan atribuye a la comunicación global pautas de regreso a las formas de comunicación cara a cara características de las convivencias tribales.

La disipación de utopía nos devuelve al ensueño del pasado, afirma Bauman. El pasado es revenant, dice Ortega y hay que "contar con él" (La rebelión de las masas, IV, p. 432). El entorno de la tribu es ambiente actual en la red, según McLuhan.

El hilo conductor del texto es el estudio de la inserción de la tecnología, especialmente la relativa al medio de comunicación, como factor de cambio histórico y de filtro para la permanencia del pasado en los procesos sociales de la comunicación humana. Es el nexo común a estos autores En este texto nos interesamos específicamente por formas de latencia de la retórica -institución

3 “Verdampft". Berman se inspira en este párrafo para titular su famosa obra “Todo lo sólido se desvanece en el aire" (1988, pp. 83 y 90). Bauman, se inspira en Berman al hablar de "liquidez". La expresión está tomada del Manifiesto comunista: "Alles Ständische und Stehende verdampft, alles Heilige wird entweiht, und die Menschen sind endlich gezwungen, ihre Lebensstellung, ihre gegenseitigen Beziehungen mit nüchternen Augen anzusehen".(Marx Engels, 1972, p. 465. "Esfuma" es la traducción española más común. 
social que reguló la argumentación mediante un conjunto de reglas durante dos milenios- en la presente circunstancia de la red, un entorno pasado ajeno a su disciplinada artesanía de la argumentación.

\section{Recuperación del lenguaje corporal en el medio audiovisual}

Estudios precedentes de la lingüística, la antropología del lenguaje y la semiología ratificaron la importancia de la comunicación no verbal a la cual Ortega había dedicado atención en los capítulos VII y X que McLuhan leyó (1971, pp. 124-125) de El hombre y la gente. El cuerpo puede ser medio del galanteo como la glotis lo es de las palabras (Knapp, 1982, p. 40). Si reparamos en la comunicación no verbal, su expresividad se muestra a través de señales transmitidas por el cuerpo. Flora Davis advierte: "pertenezco a la clase de personas que no confía plenamente en el teléfono [...] porque no puedo estar segura de lo que realmente quiere decir la otra persona. Si no puedo verla ¿cómo puedo adivinar sus sentimientos?” (1971, p. 11). Lo pertinente no es que estos trabajos enlacen con el debate que introduce McLuhan sobre el significado social de "el medio es el mensaje". Lo pertinente es que, si el medio es el mensaje, entonces también "el cuerpo es el mensaje”, como concluye agudamente Davis (1971, pp. 52 ss.) parafraseando a McLuhan.

Esta comprensión del gesto como una función expresiva que emana del organismo pensante compartiendo o completando los atributos del lenguaje oral, que los gramáticos vinculan habitualmente a la entonación, rompe con la disciplina intelectualista que subestima la pasividad del espectador ante la imagen y exalta la abstracción discursiva. Entendido el raciocinio como facultad distintiva del pensamiento, queda delimitado a una operación mental descarnada. La deliberación aspira a ser reproducida en un modelo formal. El diálogo queda centrado en una función argumentativa disociada de las manifestaciones expresivas que contribuyen a la elocución. La crítica de la razón solo es "pura" cuando la actividad crítica aísla su objeto de las circunstancias que incluyen los intereses o los sentimientos que motivan la expresividad. La racionalidad es entendida como un método o una facultad escindida de la imaginación, la emotividad, incluso de la memoria.

Si la crítica del racionalismo a la autoridad por tradición ligó la ciencia al automatismo demostrativo de una lógica apodíctica, el retorno en las redes de las condiciones interactivas propias de la proximidad audiovisual expide la carta de defunción de estas pretensiones. El idealismo ilustrado inició esta tarea tras deducir un sujeto trascendental del programa cartesiano. La teoría crítica la concluye al diluir el sujeto en la "acción comunicativa" y en la "ética del reconocimiento". La cuestión hoy no es cómo se interrumpe esa herencia cartesiana, caída del caballo tras Husserl, o si, por decaer, retorna, descontrolada, la vieja retórica en el circuito de las redes. La cuestión es en qué condiciones se restablece esa regresión en las nuevas tecnologías. Las reglas retóricas se habían venido forjando como modelo argumental de la exposición persuasiva durante dos milenios. El estudio y la observación fueron depurando pautas para ponerlas a disposición de la oratoria en los tópicos o lugares comunes que vinieron registrándose durante siglos para que el esfuerzo memorístico no interfiriera en la fluidez argumentativa del orador (Curtius, 1995).

En el nuevo ambiente post-cartesiano y anti-darwinista común al vitalismo, al pragmatismo y al interaccionismo, McLuhan comprendió que la tecnología estaba provocando una nueva "circunstancia" histórica. El desarrollo de la transferencia comunicativa por la electricidad y los medios de transporte conducía a la unificación planetaria. El Manifiesto comunista se había adelantado a referirse a un "mercado mundial". La referencia a que el progreso tecnológico pudiera ser regresivo se halla expresa en La rebelión de las masas. Ortega vio en la aceleración tecnológica un proceso de unificación de la humanidad que iba más allá del mercado, 
desde el siglo XVI ha entrado la humanidad toda en un proceso gigantesco de unificación que en nuestros días ha llegado a su término insuperable. Ya no hay trozo de humanidad que viva aparte -no hay islas de humanidad. (2005 IV, pp. 455-456).

No tenía razón Ortega en lo relativo a lo "insuperable" de "su término". Resulta extraño que, quien escribió en La meditación de la técnica que el animal humano no responde a un origen evolutivo, sino que experimenta mediante la mediación técnica un progreso histórico, pudiera estar llamado a alcanzar, en una época de plena progresividad tecnológica, un "término insuperable". Sirva de indicio de que no captaba claramente el alcance del cambio que se estaba produciendo, aunque pocos como él habían entrevisto que esa novedad empequeñecía el mundo.

Desde hace casi un siglo se habla de que los nuevos medios de comunicación -desplazamiento de personas, transferencias de productos y transmisión de noticias- han aproximado los pueblos y unificado la vida en el planeta [...] De pronto y de verdad, en estos últimos años recibe cada pueblo, a la hora y al minuto, tal cantidad de noticias y tan recientes sobre lo que pasa en los otros, que ha provocado en él la ilusión de que, en efecto, está en los otros pueblos o en su absoluta inmediatez [...] para los efectos de la vida pública universal, el tamaño del mundo súbitamente se ha contraído (2005 IV, pp. 519 y 520).

Anunció la globalización no solo como relación mercantil, como advertía el Manifiesto, sino como forma de interdependencia ubicua y simultánea de las relaciones humanas facilitada por nuevos medios de comunicación en los que prendía el novedoso fenómeno de "la rebelión de las masas". Temía que el individualismo liberal pudiera derivar en una especie de "barbarie", donde cada uno opinara caprichosamente con el fin de desprenderse de las constricciones de la regla legal, del conservadurismo moral y de la tradición alentadas por el "capitalismo". Ortega antepuso el conocimiento científico al mercado capitalista. Como había dado carpetazo a las pretensiones idealistas del sujeto puro, pensaba que la actividad de un organismo que piensa cuando siente y siente mientras piensa no puede encauzarse al modo racionalista del sujeto trascendental. El progresismo ilustrado fiaba el proceso social a una ilusión, por lo que las consecuencias del proceso de una libre opinión podrían no favorecer la cohesión social y sustituir perniciosamente los lazos emotivos donde prende la solidaridad por un individualismo insolidario. Creer que la licuefacción social era producto del proceso industrial del capitalismo era un planteamiento reduccionista ya que la eficacia de la revolución industrial sería imposible sino fuera ligada a un nuevo tipo de conocimiento.

McLuhan entrevió que esos nuevos medios, televisión y radio principalmente, reproducían en el espacio planetario global (Núñez Ladevéze; Vázquez Barrio y Núñez Canal, 2020) las circunstancias comunicativas vecinales, similares a las relaciones cara a cara de las aldeas primitivas. Por supuesto, las relaciones cara a cara no eran cosa del pasado, pues nunca se extinguieron. Al contrario, se habían expandido al abarcar toda la superficie planetaria interconectándola con medios de comunicación. McLuhan colige que el presente puede regresar al pasado, si es cierto que el pasado se conserva en el presente. Como dice Ortega

el pasado humano no pasa, si pasar quiere decir dejar de ser el pasado humano [...] persiste en todo presente [...] el hombre lleva a cuestas todo su pasado, incluso el más primitivo, es decir, lo sigue siendo y gracias a eso es hombre. El hombre es un animal que lleva dentro su historia, que lleva dentro toda la historia. No cabe definición menos darwiniana (2009 IX, pp. 1347) .

4 En Ortega el pasado está activo. El pasado es ejecutivo en el presente no menos que el futuro está activo como proyecto de quehacer en el pasado. Vivimos el pasado en el presente readaptándolo a la circunstancia en que nos hallamos y que, a su vez, nos adapta al actualizar nuestro quehacer para que el futuro se adapte a nuestro presente. Como la circunstancia es en parte imprevisible, también nuestro futuro lo es. Sobre la presencia del futuro en Ortega véase Alonso, M., 2014 
McLuhan sorbió lecturas orteguianas (Núñez Canal y Núñez Ladevéze, 2021). Había leído en la Rebelión de las masas que el hombre "acumula su propio pasado, lo posee y lo aprovecha" (V, 369). En Meditación de la técnica, que a la condición humana es inherente conservar las etapas del pasado en el presente y que la técnica es un supuesto de periodización más firme que el recambio de clases (V, 588-590). En Historia como sistema leyó que "la sociedad es, primariamente, pasado [...] Hay pasado, lo habrá como presente y actuando ahora en nosotros” (VI, pp. 69-71).

Cuando la alfabetización abstrajo del lenguaje oral sus constituyentes elementales -letra, sílaba, palabra-, permitió sustituir la evanescente transmisión oral de la memoria por su conservación escrita. Gracias a la inscripción de los símbolos alfabéticos en materiales duraderos, el lector pudo ahorrarse la fatiga de memorizar y recordar lo dicho por otro, pudo leerlo literalmente sin tener que esforzarse en recordarlo. Verba volant, scripta manent. Esto tenía ventajas e inconvenientes, como señaló Platón en el Fedro, diálogo que comentan Ortega (por ejemplo, "Misión del bibliotecario”, V, p. 367) y McLuhan (1969, p. 52). Lo relevante fue que, al reproducirse el texto por la tecnología de la imprenta, se produjo "el público" (1969, p. 8), un nuevo tipo de relación social que conectaba simultáneamente la opinión de cada uno para convertirla, según Ortega, en apremiante uso colectivo (El hombre y la gente, X, pp. 269 y ss). No se refería McLuhan a la "visualidad abstracta del alfabeto" (1996, p. 44), sino a "la nueva cultura visual de la imprenta" (1996, p. 36) para distinguirla de la relación cara a cara en vecindad y del lector del manuscrito. La imprenta delimitó el "público" (1969, p. 357) durante medio milenio en el entorno "cerrado" de la escritura alfabética, una tecnología específica, segregada de las relaciones "naturales", no artificiales, cara a cara entre vecinos.

\section{De los grupos primarios en vecindad física a la aldea tribal en la red}

Esta noción de público como multitud dispersa de destinatarios sin relación física cara a cara, que sirvió a Cooley (2006) para distinguir los "grupos primarios" de las "clases abiertas", procede de Gabriel Tarde (1986). Cooley se refirió a la familia, y a la vecindad como ámbitos de asignación de los "ideales primarios" que, a su juicio, subyacen a la democracia y al cristianismo, para contrastarlos a las "clases abiertas numerosas e impersonales [...] que absorben una parte vital del individuo sin moldearlo" (2009, p. 248 y ss.) "En el capítulo XI se refiere a que, al entrar las personas en contacto cara a cara sienten la emoción social y alcanzan las fases superiores de conciencia" (2009, p. 109)

Es la fuerza de esta distinción lo que, a nuestro juicio, ponen a prueba las redes sociales en la "sociedad líquida" (Núñez Ladevéze; Núñez Canal e Irisarri, 2018). La diferencia entre "grupo primario", entendido como resultas del contacto personal "cara a cara", y el "grupo virtual", se diluye en la red donde igualmente se estableces relaciones personales. Lo que importa matizar es que la creación de relaciones cara a cara virtuales, no procede de un salto brusco de la tecnología, sino que es consecuencia de un proceso abierto por el progreso tecnológico de la escritura. La intensidad que Cooley atribuyó a los "grupos primarios", se extiende a la vez que se debilita. Se extiende, porque la red es un ámbito donde fugazmente aparecen y desaparecen grupos. Surgen amistades, asociaciones personales, agrupaciones testimoniales, la mayoría, efímeras, se diluyen rápidamente (Núñez Ladevéze y Vázquez Rubio, 2020). Fortalece la cohesión de las relaciones primarias físicamente preestablecidas y, simultáneamente, facilita la heterogeneidad desarticulada de grupos dispersos en la fugacidad de la red (Bauman, 2017 p. 101). Resulta obvio que la

5 Para un acercamiento exhaustivo a la obra de Cooley, cfr. López-Escobar 2020. 
tecnología ha superado las primordiales limitaciones comunicativas del contacto cara a cara físico. Pero Cooley no pudo leer la Meditación de la técnica de Ortega.

McLuhan la leyó lo suficiente para confirmar que la distinción entre "relaciones personales" e "impersonales" estaba llamada a diluirse a causa de los progresos de la tecnología comunicativa. Fijándose en los métodos discursivos de la cultura popular, de la publicidad y del consumo, anunció que las tecnologías eléctricas, como radio y televisión, abrían el espacio de la opinión pública a los analfabetos, un tipo de público audiovisual, no previsto por Tarde, que la imprenta, generadora de opinión pública, había excluido al limitar el espacio público, al ciudadano alfabetizado.

La tecnología iba más allá. El teléfono y la radio habían propiciado el establecimiento de relaciones personales a través de la distancia. Sola Pool (1986), aseguró que la relación telefónica y telegráfica point to point entre dos personas sin contacto físico iniciaba una época que diluiría progresivamente las diferencias entre la comunicación personal, limitada a la presencia física, y la comunicación a distancia, al permitir que las relaciones personales pudieran ser distantes. La imbricación que Cooley hizo entre grupo primario y relación personal se deshilachaba. Veinte años después, Burke y Brigss (2002) se sirvieron de esta noción para describir el sistema de relaciones que ya esparcía internet.

La virtualidad telefónica favoreció nuevas prácticas sociales como mostró Marvin (1990). Sola Pool (1983) había salido al paso de que muy pronto los poderes públicos procurarían en las sociedades abiertas controlar este potencial comunicativo facilitado por las tecnologías eléctricas. Su recelo, no concernía a la libertad de uso de los ciudadanos, sino a la tentación del poder político de controlarlo, limitando las libertades o monopolizando esa capacidad. Nada nuevo bajo el sol. Había ocurrido con la imprenta. Hay demasiado escrito para cuestionarlo. Basta leer La Areopagítica, el libelo de Milton, para visualizar el respeto del poder político a la imprenta. Sin embargo, lo que entraba en juego con relación a las ilusiones democratizadoras favorecidas por el potencial igualitario de la tecnología es justamente lo contrario: que el igualitarismo del medio compromete normativamente al usuario porque democratiza sus elecciones. No es extraño que, con la red, también haya ocurrido -como sucedió en la prevención de Sola Pool (1977) sobre el control telefónico, y antes sobre la escritura y la imprenta- que el entusiasmo con que fueron interpretados los cambios pronto trocara en temor (Van Dijk, 2013).

El "grupo primario" se esparcía por ondas y cables. La televisión posibilitó que cada individuo, analfabeto o no, pudiera conectarse cara a cara con cualquier otro. Como advertía Ortega, allende la distancia el individuo a través del medio era promotor de opinión. McLuhan comprendió que el nuevo medio televisivo no discriminaba como la tecnología de la imprenta, al contrario, igualaba a analfabetos y públicos alfabetizados ¿Democratizaba? Un mundo interconectado por televisión, telefonía y radio restablecía planetariamente la interacción de las aldeas primitivas para regresar a las condiciones comunicativas de la aldea tribal en la global. Emergía un nuevo escenario cuyo sentido había que comprender antes que criticar. Por decirlo con Cloutier (1973), una tecnología que puede combinar lo audiovisual con lo escrito no resta, sino que suma las ventajas de una a la capacidad de la otra.

Ortega y McLuhan no se hicieron ilusiones sobre el medio como factor de democratización. Pragmáticos sobre el alcance social del progreso comunicativo, coincidieron en que las ventajas de la televisual apenas compensaba las restricciones de la imprenta. ¿La universalización de las condiciones comunicativas implicaba una democratización igualitaria que el progresismo teleológico había previsto para que la humanidad pasara de la edad de la infancia a su mayoría de edad? (Kant, 2004). ¿Significaba que la 
disolución de las relaciones de servidumbre y dominación que los ilustrados habían imputado a las condiciones sociales transmitidas por un estado infantil de la conciencia estaba al alcance del potencial de los medios comunicativos? A juicio de la Teoría Crítica antecesora de Bauman, faltaba cumplir un doble e indispensable requisito: que la relación entre emisor y destinatario fuera transitiva y no receptiva, y que, a la vez, fuera reflexiva y crítica, no una contemplación adocenada (Núñez Ladevéze, Vázquez Barrio, y Núñez Canal, 2020).

La tecnología de la red satisface el doble requisito. Si la imprenta creó un entorno visual cerrado, la televisión lo abrió al unir a la visualidad abstracta, la imagen acústica y visual concretas, hasta entonces limitadas a las relaciones de vecindad física. La "tecnología eléctrica está empezando a devolver al hombre visual, o del ojo, a los patrones tribales y orales con su trama continua de vínculos e interdependencias” (McLuhan,1996, p. 71). Después de la televisión, la relación en red era transitiva, interactiva y crítica. El pronóstico de McLuhan fue tan acertado en lo relativo a la interactividad crítica y en que suponía una vuelta a "los patrones tribales y orales", que Bauman llega a identificar el igualitarismo crítico de las redes con la "vuelta a las tribus" (2017, pp. 54 y ss.). El progreso comunicativo regresaba a la aldea primitiva en la interconexión de la aldea global. Lo que Bauman encuentra es que el usuario no lo acepta para emanciparse, lo acepta con la misma sumisa complacencia ante la reproducción tecnológica con que el hombre primitivo aceptaba sumisamente su condición tribal.

\section{De la rebelión de las masas a la regresión a la tribu}

Hay una diferencia. Parafraseando a Ortega, la tribu comunal no se elige, se está en ella. En cambio, las tribus virtuales son fugaces, se eligen o se buscan, se encuentran o se eluden, son transitorias, pueden disiparse tan pronto como se concretan, se esfuman a capricho, tan efímeras o constantes como el usuario desee. ¿Es el capitalismo? No solo. Es un fenómeno global que ocurre en todas partes. Tampoco es una pertenencia obligada por un patrón del mundo previo de la vida. Las redes son compatibles con el mantenimiento de pautas adquiridas en las relaciones primarias de convivencia en proximidad (cfr. Núñez Ladevéze y Vázquez Barrio, 2020). Cómo interfieren en esas pautas para modificarlas es una cuestión empírica. Cualquier uso de la red puede ser instrumento de interacción para un asentamiento o un desistimiento del yo y de sus automatismos (Mead, 1991). Imitan o rechazan usos ajenos, asientan o modifican la distinción personal, reafirman o impugnan cualquier status adquirido. Lo establecido es desechable a conveniencia. Tarde ya se había referido (2011) a la importancia de estos "automatismos" del uso -así los llamó Ortega, pero también podríamos denominarlo “dialéctica” de “imitación” y “distinción”, o de “asentimiento” y "desistimiento" (2010 X, pp. 269 y ss.)-. Era obvio que el proceso reproductivo de bienes culturales en masa producía una progresión regresiva gracias a la tecnología. Tal fue la respuesta de Ortega a la pregunta planteada por de la Boetie (1986) de por qué los hombres aceptan servilmente la sumisión a otro hombre por costumbre:

Después de la derrota que sufre en su audaz intento idealista, el hombre queda completamente desmoralizado [...] el hombre siente un increíble afán de servidumbre. Quiere servir ante todo a otro hombre [...] Tal vez el nombre que mejor cuadra al espíritu que se inicia tras el ocaso de las revoluciones sea el de espíritu servil (2005 III, p. 640).

Lo escribió Ortega en El tema de nuestro tiempo, anticipándose tres cuartos de siglo al discurso de Bauman al recibir el premio Príncipe de Asturias donde se lamenta de la propagación en la red de "esta inclinación incapacitadora (sic) nuestra a la que Étienne de la Boétie denominó «servidumbre voluntaria»" (2010b). La Ilustración hizo suyo el discurso de la servidumbre. Lo asumió 
como herencia de un pasado del que habría de desembarazarse. Convirtió la nostalgia por un tiempo anterior en la atadura de tradiciones de las que hay que emanciparse.

La Ilustración trató de alienante esta dependencia de la tradición. Su crítica fue el caldo de cultivo para la ideología, el idealismo ilustrado y el programa materialista de emancipación social. La pretensión igualitaria prescindía de base real donde sustentar la relación entre un yo y un nosotros. Vinculó una relación que se nutre de un nexo afectivo a las resultas de un acto reflexivo. El individualismo masificado esparce la dilución de los lazos estéticos y normativos, pero no ofrece como recambio más que la complaciente arrogancia de la rebeldía del individuo masificado cuando cada uno toma plena conciencia de que su derecho a ser o no vulgarmente analfabeto le faculta a menospreciar la norma que le exige el esfuerzo de no serlo. Se abría la puerta a una rebeldía sin causa.

El proceso de emancipación hacia la mayoría de edad requería del desprendimiento de las ataduras transmitidas como legado comunitario. Si el progreso a la cultura de masas entrañaba La rebelión de las masas, el que lleva a la aldea global refuerza esa capacidad de autoafirmación de la masificación individualizada. En la senda que conduce a la aceptación del medio como instrumento se asienta la "servidumbre voluntaria" de los procesos que hacen posible la rebelión de las masas. Para eludir la paradoja, Adorno y Horkheimer (1998) interpretaron que la masificación cultural era el producto de un designio capitalista para presentar la libertad jurídica como tapadera de una servidumbre al sistema.

Es interesante ver ahora dónde sitúa la regresión McLuhan, tantas veces malinterpretado como apóstol de la cultura de masas. Convencido de que el futuro señalado por la renovación tecnológica sustituía la cultura selectiva de la imprenta por una nueva cultura abierta a los analfabetos y ligada a la implosión de los medios comunicativos, transmisores de un igualitarismo cultural masivamente individualista, podía parecer que defendía algo así como el igualitarismo democrático de la cultura popular audiovisual frente a una cultura aristocrática, selectiva y alfabetizada a cuyas huestes aprovisionaron entre otros Spengler en $L a$ Decadencia de Occidente (1923) y Sartori en Homo videns (1998).

En la McLuhan Galaxy Conference, celebrada en Barcelona con motivo del centenario de McLuhan en 2011, solo hay un texto que relacione a McLuhan con Ortega, a pesar de que McLuhan, que menciona de pasada La Rebelión de las masas en El cliché y el arquetipo, cita a Ortega con cuidadosa atención en Guerra y paz en la aldea global, su principal obra inmediatamente posterior a Understanding Media. La visión esquemática que ofrece esa referencia a Ortega en la McLuhan Galaxy Conference da lugar en el comentario a contraponer la rebelión de las masas a la capacidad anticipadora y, en apariencia al menos, igualitarista de McLuhan:

Some, elitist and conservatives, look to the masses as if it was the embodiment of all degeneration of individual and looked at "massman" with suspicion as the most dangerous destructive power against social order [Ortega y Gasset, 2004] (García Arnau, 2011, p. 420).

Pero esta interpretación es difícilmente compatible con el pragmatismo de McLuhan y el raciovitalismo orteguiano. Es una miope simplificación (Cfr. Núñez Canal y Núñez Ladevéze, 2021). Veamos la confluencia de ambos: 


\section{Retórica en la mirada cotidiana}

"La televisión incita a la dramatización en un doble sentido: escenifica en imágenes un acontecimiento", decía Bourdieu (1996, p. 24). Si una imagen vale más que mil palabras es porque en un instante transmite una información que no puede describirse con mil palabras. El peso de la imagen medido en bites es incomparable con el del texto que la describe. Esta evidencia incita a Jeffrey Green a dignificar la información en el lenguaje transversal, abierto y concreto de la imagen transmitida, que la modernidad había devaluado en beneficio del escrito, alfabéticamente cerrado y abstracto. Desde que el giro fenomenológico hacia el vitalismo y el pragmatismo mostrase que la concreción del sentimiento ligada a la expresión del lenguaje corporal es inherente al lenguaje hablado, el acceso audiovisual recobra cierto valor intelectual perdido frente a la escritura que abstrae visualmente el contenido acústico y la imagen visible. Se hace patente que lo esencial de las relaciones comunicativas no cambia por el hecho de que se realicen unidireccionalmente en la lectura, o bien a través del intercambio hablado. Que el escritor frecuente el ensimismamiento y que el habla implique diálogo no quita que los monjes leyeran en voz alta ni que la meditación reflexiva sea monopolio de la escritura.

McLuhan comprende que, en las circunstancias favorecidas por las nuevas tecnologías, la visualización a distancia del lenguaje corporal abre el círculo cerrado por la imprenta. El medio es el mensaje, sí, pero no determina la actitud ni fija su utilidad comunicativa. Al hacer posible la radio y la televisión la participación política del ciudadano sin necesidad de tener que informarse a través de la lectura, los actores políticos difícilmente priorizarán difundir sus propuestas contenidas en programas cuando pueden hacerlo más eficaz y ampliamente en un debate o una entrevista ante las cámaras. Tampoco al espectador le importará tanto conocer el contenido de los programas para optar a favor de las propuestas de un candidato o de otro. La audiencia es un tipo de público novedoso, más igualitario por no ser "selectivo". Como descriptora, la mirada del ojo unida a la palabra oída percibe información que no aporta la lectura. Y si puede fijarse sobre una materia, o sea, reproducirse y modificarse en una moviola, también puede ser objeto de atención reflexiva tanto como lo escrito. Entonces es lógico que, quienes tienen responsabilidad como expertos y diseñadores estratégicos, estudien los gestos, ademanes, la mímica y la gestualidad empleadas por el candidato para captar la atención del espectador. Si la nueva tecnología entraña un regreso a las condiciones comunicativas de los vecindarios (Núñez Ladevéze, Vázquez Barrio y Álvarez de Mon, 2019), también significa un regreso a las condiciones argumentativas de la oratoria visual, es decir, a las artes o artimañas empleadas para cautivar al espectador ejercitando las relegadas artes retóricas.

No hacía falta que intelectuales como Bourdieu (1996) y Bueno (2001) comprendieran que, a través de la televisión, el espectador accede a la personalidad del candidato y puede sentirse atraído a su causa o rechazarla. El utillaje para suscitar esa atracción es inherente al arte retórica de la comunicación audiovisual que pretende cautivar a un auditorio de individuos que escuchan mientras miran (Núñez Canal y Núñez Ladevéze, 2021). En esas condiciones, nada obsta a que la expresividad emocional gane al espectador tanto o más que la capacidad de raciocinio, pues aporta información relevante sobre las actitudes, intenciones e incitaciones del actor. Importa, sí, que el raciocinio emocione, porque nada impide que el razonamiento sea emotivo. No hay una contraposición entre democracia deliberativa y democracia sentimental (Arias Maldonado, 2016). Aun suponiendo que fuera más deseable filtrar la emotividad como componente de la argumentación, si fuese cierto, como decía Ortega, que el sujeto deliberativo es indisociable del emocional, la pretensión será utópica. No hay razón más abstracta que la vacua matemática, pero los 
matemáticos pueden ser tan sensible a la retórica como el resto de sus congéneres. Nadie es invulnerable a la demagogia como presumía Maquiavelo.

De aquí que la propuesta de Jeffrey Green (2009) de realzar la relevancia de la imagen audiovisual como instrumento de regulación y de participación democrática en la sociedad digitalizada pueda contraponerse a las pretensiones de que la participación asamblearia responda al discurso deliberativo mejor que la representación indirecta. En primer lugar, porque la participación directa no es el mensaje. Nada garantiza que el discurso entre participantes responda a un debate donde el componente deliberativo prevalezca sobre el emotivo. (Arias Maldonado, 2016). Si la emotividad no es segregable de la deliberación, puede reforzarla tanto como debilitarla. Una misma argumentación puede ser más eficaz si emociona que si no emociona. En segundo lugar, porque los participantes en una asamblea son minorías que acceden a ella por selección social (Zaller, 2014). No todos los concernidos están en condiciones o tienen las mismas oportunidades para participar. En tercer lugar, como la división de tareas hace socialmente selectivo el proceso, los asamblearios ostentan un plus de representatividad del pueblo que el populismo tiene que construir (Laclau, 2005). Por último, la formación de opiniones generada en los grupos primarios no está, como mostraron las teorías del doble flujo, predeterminada por la exposición al medio. De lo que resulta que el liderazgo en el grupo primario es un ingrediente que simplifica, complementa y colabora con la decisión del elector.

Este análisis pragmatista fue incoado por Cooley, al insistir en la formación del yo en grupos primarios, y por Lippmann (1964), al incidir en la formación de la opinión política por medio de relaciones cara a cara interpersonales. Goffman las define "como la influencia recíproca de un individuo sobre las acciones del otro cuando se encuentran ambos en presencia física inmediata” (1981, p. 27). Anticiparon los estudios sobre la influencia personal en la formación de la opinión pública. Zaller completó un sólido modelo de formación de la opinión política que remonta a Lippmann (Zaller, 2014, pp. 28 y 37). El modelo RAS, elaborado a partir del examen de pregunta respuestas en encuestas electorales tiene el mérito de integrar los cuatro puntos antes señalados. Según Zaller. los ciudadanos se distribuyen en sectores distintamente interesados sobre los temas políticos. De aquí que la formación de su opinión sea dependiente de líderes de opinión que tienen información precisa sobre los temas y una idea explícita sobre sus implicaciones sociopolíticas y doctrinales. No se trata de distinguir entre ciudadanos de segunda y ciudadanos de primera, sino de admitir la evidencia de que "somos consumidores de segunda mano de ideas originadas en la distancia en el seno de alguna élite [...que] incluye a los políticos, los funcionarios de alto nivel, los periodistas y algunos activistas y muchos tipos de expertos y especialistas de la política" (2014, p.28).

Zaller mostró, siguiendo a Lippmann, que, en la sociedad civil, profesionalmente ajena a la política, el ciudadano no dispone de tiempo para informarse ni tiene interés inmediato para hacerse una opinión sobre los temas acerca de los que se le interroga. Los estudios sobre doble flujo, los relativos a la formación de la agenda setting y los análisis de los marcos de referencia, noción extrapolada de la microsociología de Goffman sobre la interacción en la vida cotidiana, mostraron que la adopción de criterios para decisiones políticas ocupa un lugar secundario, sin que eso signifique que desmerezca la condición intelectual. El rango de autoridad en alguna rama de la actividad profesional, artesanal, comercial o artística no coincide con el liderazgo de opinión sobre asuntos públicos. Pero la obra de Goffman (1981), heredera de la formación del "self" de Mead (1991), se basó en la persistencia del pasado. Estudió relaciones cotidianas como organización de normas entre personas en proximidad cuya cara está al alcance de la vista (Sánchez de la Yncera, 1995), un espacio que ahora se abre a un terreno de relaciones a distancia en la red. 
Aunque la relación entre Ortega y el pragmatismo norteamericano fuera escasa ${ }^{6}$, lo pertinente de la propuesta de Zaller radica en que, sin referirse a ella, reproduce el sentido subyacente de la distinción entre mayorías y minorías que Ortega había suscrito en La rebelión de las masas y otras obras. Las enlaza para apartarlas de la pretensión idealista de situar la reflexión como rasgo distintivo de la racionalidad. Al apreciar que todos los componentes de la mayoría social pueden ser considerados minorías o autoridades relevantes en una disciplina, oficio, comercio, artesanía, u otro ámbito, como el deportivo o la moda, puede parecer que se corrigen aspectos sustantivos del planteamiento orteguiano. Pero no era eso lo que Ortega advertía al referirse a una rebelión de las masas, sino justamente lo contrario. Lo que decía es que cualquier motivo para apreciar un mérito resulta contaminado por la pretensión de autonomía estética y moral del individuo, es decir, por la insumisión a la norma del respeto al mérito, al que más sabe, mejor enseña o mejor trabaja en su arte.

Volvamos a Green. Las diversas facetas de la vida cotidiana no tendrían sentido sin referencia a la mirada escrutadora. Si somos espectadores en la vida corriente nada tiene de extraño que la vista sea el órgano empleado para participar como ciudadanos en la pública. Habitualmente la mayoría solo dispone de tiempo para observar cómo actúan los políticos. La observación es una fuente de información cuyos componentes pueden ser de diverso grado y compatibles con la capacidad de reflexión. La interpretación crítica detallada y el análisis de sus programas y actividades queda reservada a especialistas. Pero el observador puede discriminar, atendiendo a la expresividad de la imagen más que a la exposición discursiva, entre los motivos de confianza y de desconfianza del orador, el ethos de sinceridad o simulación, de conocimiento o incultura transmitido en el discurso. Al leer un programa no se captan las intenciones de su redactor. El lenguaje corporal visible procura información inaccesible a una concepción abstracta de la racionalidad.

La tesis de Green devalúa los recelos que frecuentemente suscitó la imagen como medio de comunicación frente a la palabra oral o escrita. Hace saltar por los aires la crítica centrada en que el progreso tecnológico vinculaba la imagen y el espectáculo a la pasividad de la audiencia ante la pantalla. Desconecta la abstracción intelectualista de la inteligencia sentiente. No habla de masas, sino de participantes que, si en la vida suelen ser espectadores del acontecer, no tienen motivos para dejar de serlo cuando se trata de administrar asuntos públicos. Normalmente somos observadores pacientes de cómo actúan aquellos en los que confiamos cuando nos ponemos en sus manos si vamos al hospital, al comercio o al especialista. El observador entiende a qué se expone cuando mira y escucha, pero leer un programa no acerca más a comprender la retórica emocional del pathos que anima las intenciones de su redactor. Los comentaristas más autorizados describen, como característica principal de la nueva tecnología, su capacidad para que todo individuo pueda contrastar sin restricciones las imágenes del mundo en pantallas interconectadas o en el fluido individualizado de las redes. Mirando y hablando por ellas sabemos lo que ocurre allende nuestra limitada experiencia (Lipovetsky y Serroy, 2009). Los ilustrados leían a distancia, miraban o escuchaban en la proximidad, ahora leemos, escuchamos y miramos en la distancia y en la proximidad. Como anticipaba Ortega y certifica McLuhan las proporciones del mundo se han reducido al entorno de una aldea global al alcance de la vista y del oído de cualquiera.

6 Para detalles y bibliografía remitimos a las tesis doctorales de Armenteros 2003 y de Gutiérrez Simón, 2020. Nubiola ha venido prestando atención a la relación entre Ortega y el pragmatismo, principalmente de Peirce, Cfr. (2019). El sesgo pragmático de Ortega se puede seguir sobre todo el capítulos II, III, y VI de $E l$ hombre y la gente. Nos hemos ocupado de ello en Núñez Ladevéze, Núñez Canal y Álvarez de Mon, 2021. 


\section{De la artesanía retórica al desencanto de las redes}

Tal como lo ve McLuhan, más atento en esto que Ortega, "la imprenta, o escritura mecánica, introdujo una separación y una extensión de las funciones humanas [...una] asombrosa técnica de análisis espacial que se duplica a sí mismo en el acto" (1996, pp. 118 y 132). No es necesario excitar la imaginación para entender que esta "separación" refleja la disociación cartesiana de la potencia reflexiva y la urdimbre sensorial. Por supuesto, la imprenta no la explica, pero da pie a la concepción reduccionista del hombre como sujeto reflexivo. La lectura permite volver sobre lo leído, pensar sobre lo pensado, reflexionar, meditar agarrando cada palabra, despiezando el párrafo, descomponiendo el texto para rectificarlo o modificarlo. Platón había observado en Fedro que la escritura era un remedio para la fragilidad de la memoria literal. El lector alfabético es más inmune que el iletrado a que el hilo del razonamiento se pierda en el recuerdo. Pero le escritura no es un sustitutivo sino una prolongación del habla de la gente por un medio técnico. En ella el pasado hablado permanece.

En la milenaria tradición retórica, el ejercicio de la memoria era una artesanía imprescindible para asegurar la eficacia persuasiva. El orador la ejercitaba aprendiendo reglas mnemotécnicas y cultivando lugares comunes o tópicos, para limitar el esfuerzo expositivo y minimizar los riesgos de la repentización. La retórica ligaba normativamente el pathos y el ethos entre orador y auditorio. Servía como control de calidad de la argumentación. No entendía la exposición como manifestación de una facultad abstracta ocupada en extender al lenguaje las pretensiones de una lógica apodíctica. Esta pretensión se hizo patente en el Novum Organum, antecedente del imperativo racionalista que apremia a la crítica de la razón pura desde el cogito cartesiano. Recompuesta la unidad argumentativa de un organismo que piensa y siente, la retórica encuentra una puerta de regreso en la antropología, el pragmatismo filosófico, el interaccionismo..., a world that is there, escribía Mead (1991, p. 166).

Por esa puerta regresa a la aldea tribal un especialista en literatura medieval. Observa que la imprenta tardó en romper el lazo que ligaba la artesanía retórica a la tradición intelectual argumentativa. Como decía Ortega, los lazos del pasado perviven en el presente. Con Curtius, McLuhan suscribe la tesis de Treveylan de que "las maneras medievales de vida subsisten hasta mediados de 1750" (Curtius, 1955, p. 813).

Este aspecto oral de la cultura del manuscrito no solo afectó profundamente la manera de componer y escribir, sino que también significó que la escritura, la lectura y la oratoria permaneciesen inseparables hasta bastante después de la imprenta (McLuhan, 1969a, p. 87).

No es responsabilidad suya que la retórica clásica, cuyas reglas obedecen a un arte que se ha ido perfilando y socializado durante dos milenios, haya perdido su campo de aplicación por la traslación del interés científico a la lógica y la matemática. La búsqueda de un lenguaje lógico, exacto, que sustituya a la imperfecta lengua materna ha sido constante desde la modernidad. La retórica va perdiendo sentido a medida que lo gana el tratamiento científico de la gramática, como la de Port Royal, pero, sobre todo, tras el Leviatán, cuya primera parte es una filosofía del lenguaje anti lingüística. Mientras el arte de persuadir se mirase en los modelos matemáticos y el cálculo, lógico el habla de la gente tenía que ser inapropiado para la depuración racional (Perelman y Olbrechts-Tyteca, 1970).

Si el racionalismo ligaba la ciencia al automatismo demostrativo, el retorno de las redes a las condiciones interactivas audiovisuales expide la carta de defunción de las pretensiones racionalizadoras del sujeto trascendental. La cuestión hoy no es cómo se interrumpe esa tradición cartesiana o si al decaer una lógica discursiva se renueva la tradición retórica. La cuestión a plantear 
es en qué condiciones se restablece esa tradición con la difusión de las nuevas tecnologías. Las reglas retóricas se habían venido forjando como modelo argumental del pensamiento demostrativo desde Aristóteles. Servían de control de calidad del orador. No estaban obligadas a satisfacer una razón abstracta ni a servir de instrumento a una pretensión de racionalidad. Constituían una institución para el ejercicio artesanal del discurso donde el ethos formaba parte del arte de persuadir al auditorio. Según su intensidad pueden ser éticas (ethos) o patéticas (pathos) (Lausberg, §43,2,b y \$\$69-70). El estudio y la observación fueron depurando las pautas normativas de la mnemotecnia puestas a disposición de los distintos tipos de discurso en los tópicos o lugares comunes que vinieron registrándose durante siglos para que el esfuerzo memorístico no interfiriera en la fluidez argumentativa o expositiva.

Lo que Ortega no desvela claramente en La rebelión de las masas es que esos controles de calidad, que actualmente se aplican análogamente para discernir los papers publicables, la clasificación de las editoriales, para asegurar la adecuación a las funciones académicas, para acreditar socialmente el conocimiento científico adquirido, u otras reglas socializadas que se presumen, aunque se estaban perdiendo en lo relativo a los criterios del gusto estético, se renuevan en la deontología del rigor informativo y cognoscitivo. Son muchas las reglas que se aplican como garantía de funciones análogas a las que satisfacía el arte retórica para certificar la confianza social. La multiplicación del consumo y la conversión del consumidor en usuario ha favorecido la implantación de instrucciones que actúan como controles de seguridad en el intercambio consumista en la red. Los consumidores aprenden cuándo pueden fiarse o cuándo no de los servicios y los pagos por bizum. La fiabilidad adquiere valor social justamente cuando el flujo de transferencia permite que florezcan las artes del engaño. Ocurre con la reputación corporativa, tan cuidada por las grandes corporaciones (Núñez Ladevéze, Irisarri y Morales, 2015). El entorno cognoscitivo de la difusión científica ha sustituido la deontología retórica por una normativa academicista. La redacción, las citas, el contraste de fuentes, la revisión por pares, los prontuarios profesionales, a veces esclerotizados, han tomado su lugar. Puede decirse que la retórica sobrevive transformada en procedimientos esquemáticos de revisión de textos científicos y en reglas de deontología profesional en el tratamiento de la información veraz y de la opinión ecuánime. Pero en las redes, donde el tráfico discurre sin control, la desinformación y la opinión circulan desbocadas y solo queda como regulador el hecho de encontramos simultáneamente igualados como internautas de un espacio global sin normas que se distribuye para que cada uno encuentre lo que agrade a su paladar. La red tienta al populismo. Esto es lo que alarma a Bauman.

También es lo que Ortega anticipó en La Rebelión de las masas: "Lo característico del momento es que el alma vulgar, sabiéndose vulgar, tiene el denuedo de afirmar el derecho a la vulgaridad y lo impone donde quiera" (IV:380). Emergen los rumores, las falacias, los argumentos sofísticos. Fake news es el anglicismo para referirse al descontrol de la desinformación en el igualitarismo de la red. Al extender las relaciones presenciales cara a cara a la esfera pública, la tecnología comunicativa ha disipado la frontera que separaba el rumor y el bulo propios del espacio privado, de la información contrastable en los medios informativos. Blanco (2020) ha advertido rasgos que distinguen "la precaria influencia" de los hechos, que es lo propio de las fake news, de la posverdad, "una realidad intangible". Bauman lamenta que la adhesión a la tribu prevalezca sobre la comprobación, que se anteponga al cotejo o a la refutación. El esfuerzo por hacer valer el relato propio sobre el ajeno hace prácticamente imposible comprobar los ingredientes de verdad o de falsedad de uno $u$ otro $(2017,54$ y ss).

En esa "realidad intangible" cada uno acepta o rechaza lo que le viene en gana, admite lo que necesita reforzar para asentarse y desecha lo que pone en entredicho sus creencias primarias o secundarias. Estas preferencias selectivas ya las habían advertido 
los funcionalistas al tratar de la influencia personal, lo que dio lugar a la teoría de la incoherencia cognoscitiva de Festinger, que también tiene traducción como incoherencia pragmática (Nuñez Ladevéze y Pérez Ornia, 2002). No cabe apelación social que lleve a diferenciar o separar la verdad de la mentira, porque esta distinción es pre-social, o, si se prefiere, objetiva. La retórica clásica reunió necesarias reglas deontológicas aceptadas por depuración secular de una tradición milenaria para enseñar a distinguir entre ecuanimidad y exasperación, que llevaran a separar y comprender las causas de la indignación de los motivos de esperanza. Si actualmente resulta inevitable la confusión es porque el imprevisible entramado de las redes ha roto los lazos con las reglas que permitían confiar en el arte retórica.

Los recursos para la retórica deliberativa que empapan las redes son inmunes a cualquier disciplina argumentativa que inspire confianza. La calidad es generalmente un asunto deontológico (Núñez Ladevéze, 2015), pues se conserva allí donde la deontología, como principio regulativo de un comportamiento profesional o especializado, encuentra un "campo pragmático" de aplicación (El hombre y la gente, X, cap. III y IV). Como en la red todos los gatos son más pardos que en la Fenomenología del espíritu, la indiferenciación sirve de envoltorio común a las actitudes más recriminatorias que circulan indiscerniblemente abrazadas con las más sublimes.

Esa indiferenciación caprichosa entre los ardides para alimentar el deseo o rehacer la propia identidad del grupo cuando se ve amenazada por el ajeno, por un lado, y la adecuación a los hechos, la ecuanimidad y los argumentos normativamente disciplinados por la retórica, que distinguen la autoridad intelectual de la audacia ignorante, es lo que Ortega llamó rebelión de las masas y Bauman vuelta a Hobbes y a las tribus. La retórica clásica entendió la expresividad del pathos como un vínculo entre emisores y destinatarios de la argumentación. En las redes, la apelación emocional ha dado paso a un mercadillo descontrolado de intereses que se nutren de la exaltación, animadversión o arbitrariedad. Las pulsiones nacionalistas e ideológicas, los impulsos y preferencias de gusto de tribus efímeras que conviven con los vínculos consanguíneos estables, llevó a Bauman a volver sobre la manifestación global de la "servidumbre voluntaria". La retórica ha sido sustituida por la rebelión del individuo igualado comunicativamente en la malla digital, ahora convertida en un entorno donde la igualdad de acceso es el ingrediente para compartir una servidumbre voluntaria al proceso en red.

La coexistencia de criterios sin motivación, larvada mientras la atención se centró en los rasgos igualitarios de la aldea televisiva, ha eclosionado a partir de la implantación de la red como medio de comunicación de la aldea global, más igualitaria si cabe, por ser un escenario de interacciones recíprocas de usuarios individualizados y a veces anónimos. La esperanza en la indignación se evaporó tan rápidamente como habían despertado las expectativas de los ilusos. Pasaron a ser instrumentos de una "servidumbre voluntaria" al proceso de reproducción del sistema, independientemente de que sea o no capitalista, estadounidense, indio, chino o islámico. Su espectacular y rápido arraigo, las posibilidades de libre acceso a toda fuente de información, la capacidad de establecer relaciones personales ilimitadas sin barreras espaciales, el anonimato y el desconcierto, ha contribuido tanto a incrementar las preocupaciones como a hundir las ilusiones sobre su virtualidad emancipadora. 
Llegada la red, que tantas expectativas suscitó entre los cultivadores del progresismo, basta compartir con Bauman que

el espacio y el tiempo ya no limitan los efectos de nuestras acciones, nuestra imaginación moral no ha progresado mucho más allá del nivel que alcanzara en tiempos primigenios. Las responsabilidades que estamos dispuestos a compartir no van tan lejos como la influencia que nuestro comportamiento cotidiano ejerce sobre las vidas de personas cada vez más distantes de nosotros (2010a, p. 108).

Los motivos que conducen a Bauman al pesimismo son los contrarios de Ortega. Si el diagnóstico orteguiano de La rebelión de las masas tiene vigencia no es porque sea decepcionante. Ortega no es pesimista porque piense que la rebelión sea un retroceso, es pesimista si se le enjuicia desde el punto de vista de quienes todavía se sientan concernidos por pretensiones idealistas. Convertida la esperanza en "desencanto", por utilizar un calificativo de Bauman, como ni Ortega ni McLuhan se hicieron ilusiones sobre este particular, no se hallan entre los desencantados. "Ahora todo el mundo es un sabio", escribe McLuhan (1969b, p. 14) irónicamente como si hubiera leído "la barbarie de la especialidad" en La rebelión de las masas. El pesimismo aflora entre quienes asumieron la trivialidad pretenciosa de una modernidad que, enfrentada a sus propias ilusiones de eliminar los encantamientos, se declara descontenta. Puesta la razón sobre los pies, la ilustración se convirtió en una estrategia de dominación de unos por otros que planificó la lucha de clases para traer la igualdad y la libertad entre los hombres. El pesimismo de Bauman procede de que, habiendo aceptado estas pretensiones, venga a reconocer que el camino recorrido lleva "de vuelta a las tribus". La servidumbre de las "tribus" nutre un descontento que no difiere en el diagnóstico global de la advertencia de que rechazar el pasado pudiera traer "la rebelión de las masas".

Bauman (2001) recuenta los "descontentos" de la postmodernidad. Ortega no se dejó embaucar por la técnica crítica del "desencantamiento". Las redes globalizan las condiciones comunicativas de un estadio primigenio restituido por la implosión tecnológica que no puede aplicar, en ese progreso regresivo, las normas comunitarias de las tribus. En la red todo individuo sabe lo que quiere cuando lo que quiere es conectarse para dominar a o influir en el otro. El problema actual es cómo recuperar lo perdido del arte retórica para restablecer una confianza deliberativa en el entramado comunicativo de la red.

\section{Agradecimientos}

Este artículo ha sido traducido al inglés por Charles E. Arthur.

\section{Referencias bibliográficas}

Adorno, T. y Horkheimer, M. (1998/1947). Dialéctica de la ilustración. Fragmentos filosóficos. Madrid: Trotta. Alonso, M. (2014). “El problema de la futurición en Ortega y Marías”. Revista de Estudios Orteguianos, 29, pp. $155-182$.

Arias Maldonado, M. (2016). La democracia sentimental. Política y emociones en el Siglo XXI. Barcelona: Página Indómita. Aristóteles (1953). Retórica. Tovar (ed.), Madrid: Instituto de Estudios Políticos (CEPC).

Armenteros, E. (2004). El pragmatismo de Ortega. Una “impronta" de su filosofía. Tesis doctoral. Universidad de Sevilla, idus. Recuperado de https://bit.ly/36m4JED 
Barrena, S. \& Nubiola, J. (2013). Charles S. Peirce (1839-1914): un pensador para el siglo XXI. Pamplona: EUNSA.

Bauman, Z. (2001 [1997]). La posmodernidad y sus descontentos. Madrid: Akal.

Bauman, Z. (2010a). Mundo consumo, Ética del individuo en la aldea global, Barcelona: Paidós

Bauman, Z. (2010b). Discurso de recepción del premio Príncipe de Asturias. https://bit.ly/2Su6UQr

Bauman, Z. (2017). Retrotopía. Barcelona: Espasa-Paidós.

Berman, Marshall (1988/1982). Todo lo sólido se desvanece en el aire. La experiencia de la modernidad, México: Siglo XXI,

Blanco Alfonso, I. (2020). Posverdad, percepción de la realidad y opinión pública. Una aproximación desde la fenomenología. Revista de Estudios Políticos, 187, pp. 167-186. https://doi.org/10.18042/cepc/rep.187.06

Bourdieu, P. (1996). Sobre la televisión. Barcelona: Anagrama.

Bueno, G. (2001). Telebasura y democracia. Barcelona: Ediciones B.

Burke, P. \& Briggs, A. (2002). De Gutenberg a Internet: historia social de los medios de comunicación. Madrid: Taurus.

Cloutier, J. (1973). La communication audio-scripto-visuelle á l'heure des self-media ou l'ère d'Emerec. Montreal: Presses de l'université.

Cooley, Ch. (1906). Social organization; a study of the larger mind. New York: Scribner's son.

Curtius, E. (1955, II [1948]). Literatura europea y edad media latina. México: FCE.

Davis, F. (1971). La comunicación no verbal. Madrid: Alianza.

Diamond, A. S. (1979 [1954]). Historia y orígenes del lenguaje. Madrid: Alianza.

García Arnau, A. (2011). From 'homo typographicus' to 'homo digitalis'. En M. Ciastellardi, C. Miranda de Almeida \& C. Scolari (Eds.), McLuhan Galaxy Conference Understanding Media, Today, Barcelona: UOC, pp. 420-430.

Goffman, E. (1981). La presentación de la persona en la vida cotidiana. Buenos Aires: Amorrortu.

Green, J. (2009). The Eyes of the People: Democracy in an Age of Spectatorship. Oxford univ. Pres.

Gutiérrez Simón, S. (2020). Ortega y Gasset y el pragmatismo norteamericano. Revista de Estudios Orteguianos, 40, pp. 185-197.

Kant, I. (2004/1784). ¿Qué es la Ilustración? Madrid. Alianza.

Knapp, M. (1982). La comunicación no verbal. El cuerpo y el entorno. Paidós: Barcelona.

La Boétie, Étienne de (1986). Discurso de la servidumbre voluntaria o el Contra uno, trad. José María Hernández-Rubio, Madrid: Tecnos.

Laclau, E. (2005). La razón populista. Buenos Aires: FCE.

Lausberg, H. (1975). Elementos de retórica literaria. Madrid: Gredos.

Lenneberg, E. (1973). Fundamentos biológicos del lenguaje. Madrid: Alianza.

Lipovetsky, G. y Serroy, J. (2009). La pantalla global. Cultura mediática y cine en la sociedad postmoderna. Barcelona: Anagrama. Lippmann, W. (1964 [1922]). La opinión pública. Buenos Aires: Fabril. 
López-Escobar, E. (2020). Charles E. Cooley Una aproximación. Bases para una teoría comunicativa de lo social. [Tesis doctoral inédita]. Universidad de Navarra.

Marvin, C. (1990). When Old Technologies Were New: Thinking About Electric Communication in the Late Nineteenth Century. Londres: Oxford.

Marx, K. y Engels, F. (2017/1848). El manifiesto comunista, Madrid: Península, pp. 43-91.

Marx, K. y Engels, F. (1972). “Manifest der Kommunistichen Partein”, Werke, (Karl) Dietz Verlag, Berlin. Band 4,6. Auflage Berlin: DDR. S., pp. 459-493.

McLuhan, M. (1969a [1962]). La galaxia Gutenberg. Madrid: Aguilar.

McLuhan, M. (1969b). Contraexplosión. Buenos Aires: Paidós.

McLuhan, M. (1971). Guerra y paz en la aldea global. Barcelona: Martínez Roca.

McLuhan, M. (1996 [1964]). Comprender los medios de comunicación. Las extensiones del ser humano. Barcelona: Paidós.

Mead, G. H. (1991[1925]). “La génesis del self y el control social”. REIS 55, pp. 165-181.

Nubiola, J. (2019). Ortega y Gasset y el pragmatismo. Recuperado de https://bit.ly/3l1pP10.

Núñez Canal, M. y Núñez Ladevéze, L, (2021). "Understanding the revolt: Man the technician in global rhetoric". Communication \& Society (aceptado 26 de 2021).

Núñez Ladevéze, L. (2015, coord.) Periodismo en la red: géneros, estilos y normas. Madrid: Universitas.

Núñez Ladevéze, L. Irisarri, J. A. y Morales, B. (2015): “La responsabilidad social propia de las empresas de televisión de amplia cobertura: contenidos de riesgo" Comunicación y sociedad, No 28, 3, pp. 65-82. https://doi.org/10.15581/003.28.3.65-81

Núñez Ladevéze, L., Núñez Canal, M. e Irisarri Núñez, J. A. (2018): “Pautas de integración cultural y política de la sociedad de medios masivos en la sociedad red”. Revista Latina de Comunicación Social, 73, pp. 184 a 207. http://www.revistalatinacs.org/073paper/1252/11es.html DOI: 10.4185/RLCS-2018-1252

Núñez Ladevéze, L. y Vázquez Rubio, T. (coords. 2020). Redes fugaces. De las audiencias masivas a las audiencias reticulares. Madrid: Síntesis.

Núñez Ladevéze , L., Vázquez Barrio, T. y Núñez Canal, M. (2020): "El tránsito a la modernidad líquida global: la rebelión de las masas en el vecindario indefinido”. Arbor, 196 (797): a568. https://doi.org/10.3989/arbor.2020.797n3005

Núñez Ladevéze, L., Núñez Canal, M. y Álvarez de Mon, I. (2021). “Límites del campo empírico en el observatorio de la red”. En Sotelo, Joaquín y González, Joaquín. Digital media. El papel de las redes sociales en el ecosistema educomunicativo en tiempos de Covid-19, Madrid: McGrawHill, pp. 963-981.

Ortega y Gasset, J. (2004-2010). Obras Completas. 10 vols. Madrid: Fundación José Ortega y Gasset/Taurus, 2004-2010. (Todas las referencias de Ortega son de esta edición. Título en texto. Tomo en romanos).

Perelman, Ch. y Olbrechts-Tyteca, L. (1971). Traité de l'Argumentation. La nouvelle rhétorique. Université libre de Bruxelles. 
Pérez Ornia, J. R. y Núñez Ladevéze, L. (2002). "Los gustos de la audiencia infantil y la programación televisiva”. REIS, No 99: 112-145.

Popper, K. (1961) La miseria del historicismo. Madrid: Taurus.

Sánchez de la Yncera, I. (1995). La mirada reflexiva de G.H. Mead. Madrid: CIS.

Sartori, G. (1998). Homo videns. La sociedad teledirigida. Madrid: Taurus.

Sola Pool, I. (1977 ed.). The Social Impact of the Telephone. Cambridge, Mass: The MIT Press.

Sola Pool. I. (Ed.) (1983, ed.). Technologíes of Freedom: On Free Speech in an Electronic Age. Cambridge, Mass:Harvard University Press.

Spengler, O. (1923-27). La decadencia de Occidente. Madrid: Espasa.

Tarde, G. (1986 [1904]). La opinión y la multitud. Madrid: Taurus.

Tarde, G. (2011). Las leyes de la imitación y la sociología. Madrid: CSIC.

Van Dijk (2013) Digital Democracy: Vision and Reality. En Snellen, I. \& Van de Donk, W. (Eds.). Public Administration in the Information Age: Revisited. Amsterdan: IOS-Press. https://bit.ly/351VRo9

Zaller, J. R. (2014 [1992]). La naturaleza y los orígenes de la opinión pública. Madrid: CIS. 
